\title{
Development of Questionnaire on Emotional Labor among Primary and Secondary School Teachers
}

\author{
Yanling Liu ${ }^{1}$, Dajun Zhang ${ }^{1}$ \\ ${ }^{1}$ School of Psychology of Mental Health Education Research Center, Southwest University, Chongqing, China \\ Correspondence: Yanling Liu, Mental Health Education Research Center, The Southwest University, Chongqing, China
}

Received: October 10, 2014 Accepted: October 21, 2014 Online Published: December 9, 2014

doi:10.11114/jets.v3i1.551 URL: http://dx.doi.org/10.11114/jets.v3i1.551

\begin{abstract}
In this study, based on the analysis of existing definitions of emotional labor, operational definition of teachers' emotional labor is given and questionnaire on emotional labor among primary and secondary school teachers is developed. Research results: exploratory factor analysis shows that teacher's emotional labor involves three dimensions including surface acting, active deep acting and passive deep acting; the questionnaire has good reliability and validity; confirmatory factor analysis shows that emotional labor questionnaire involving three factors is established, which further verifies the validity of scale on emotional labor among primary and secondary school teachers.
\end{abstract}

Keywords: primary and secondary school teachers, emotional labor, questionnaire development

\section{Introduction}

Emotional labor, first put forward by Hochschild (1979), refers to situations wherein employees are required to display emotions that may differ from the emotions they actually feel. Employees' emotional labor is for the salary, so it has the value of exchange.

Hochschild(1983), according to the definition of emotional labor and degree of emotional labor burden, proposes 6 types of professional emotional labors in most works. Among of them, teachers are considered as professional and technical occupation which needs high emotional labor(Adelman, 1989), which is determined by the teacher' $\mathrm{s}$ professional characteristics and requirements. Teacher occupation requires the teachers keeping stable emotion and displaying a kind, positive and joyful emotion, which is because emotion is closely related to individual's cognition and behavior(Goodwin, Groth, \& Frenkel, 2011), i.e., positive emotion will make the teachers have active thinking, improve teaching efficiency and stimulate students' interest in learning, while negative emotion will make the teacher hinder thinking, have difficulty to smoothly complete teaching content, and cause the students' depression, tension, anxiety, and even weariness and fear of learning.

Through the teachers involve high emotional work, empirical studies on teachers' emotional labor is scarce, because the study on emotional labor is put forward and performed in organizational behavior and organizational behavior researchers mainly focus on enterprises, thus most existing researches mainly involve enterprise employees, especially employees in service industry(Ashforth \& Humphrey, 1993; Grandey, 2003; Morris \& Feldman, 1996), while education psychology researchers rarely focus on the study of this field. As a result, research on emotional labor among teachers not only can enrich emotion psychology, expand education psychology but also can help teachers efficiently choose emotional strategy and manage own emotion so as to promote the teachers' mental health.

After Hochschild put forward the definition of emotional labor and carried out researches, increasingly researchers began to be interested in emotional labor. The researchers first only regarded emotional labor as a unidimensional structure involving expression intensity and frequency, and later researchers tended to consider emotional labor as a multidimensional structure (Yin, 2012; Liao Xiaoan, 2011; Zhang Huihua, Ling Wenquan \& Fang Liluo, 2006). It can be seen from the multidimensional structure analysis that different dimensions focus on different aspects of emotional labor. In conclusion, multidimensional structure of emotional labor mainly involves the following structural elements: frequency of emotional expression, degree of attention to expression rules, diversity of required expression, emotional disorder, emotional effort, surface acting, deep acting, basic emotional expression, degree of emotional diversity, degree of interaction, intensify of emotion, emotion performance persistence, etc. However, there are still big divergence on definition and measurement of emotional labor. As a consequence, we should find the nature and core element of the 
structure of emotional labor from existing literatures.

From the definition of emotional labor, although different researchers put forward different definitions from different perspective, they all argue that emotional labor involve emotional adjustment and management in work (Diefendorff \& Gosserand, 2003; Sun Juncai \& Qiao Jianzhong, 2005). Consequently, we define emotional labor as a process of necessary adjustment and management of own emotion to express the organizational required emotion.

From the perspective of the structure of emotional labor, although the researchers put forward different structure dimensions, core structure is emotional adjustment and management strategy - surface acting and deep acting of emotional labor, while frequency of emotional expression and degree of attention to expression rules and diversity of emotional expression belong to the feature of emotional labor, rather than the nature(Kruml \& Geddes, 2000). On emotional effort and emotional disorder, Hochschild argues that emotional management needs emotional effort, but how can emotional effort be achieved? What is the way of effort? These questions are not clear; and emotional disorder is a state, rather than a process which needs effort, because emotional disorder is not an emotional labor. However, surface acting and deep acting are important component for almost all the questionnaires. Surface acting involves management of observed external expression, and deep acting (including active deep acting and passive deep acting) involves management of internal emotion(Grandey, 2000), which is in accordance with of our definition that emotional labor is a process of emotional adjustment and management. In addition, structural dimension of emotional labor involving surface acting and deep acting has the following advantages: first, surface acting and deep acting themselves are of no value and may have positive and negative results; second, emotional labor involving surface acting and deep acting can build relationship with the existing researches, thus there will be reference when comparing the results.

According to the analysis above, we operationally defines teachers' emotional labor as a process of teachers' necessary adjustment and management to display emotion suitable for education teaching activities in order to complete the education teaching task assigned by the school. We construct three dimensions of teacher's emotional labor including surface acting, active deep acting and passive deep acting. On the basis of structural dimensions of teacher's emotional labor, we carry out the flowing questionnaire development.

\section{Development of Primitive Questionnaire on Emotional Labor among Primary and Secondary School Teachers}

\subsection{Open Questionnaire Survey}

First of all, in order to determine whether the definition of structure dimension of teacher's emotional labor is reasonable, open questionnaire investigation among 150 primary and secondary school teachers in Chongqing and Sichuan was carried out and 103 valid questionnaires were received. The items of the questionnaire involve: what is your emotion will be when your emotion in the work is not the required one of the school? (For example, pretend to display the required emotion, directly display own emotion or display the required emotion after adjustment). Teachers' answers are encoded. It is found that Chinese teachers also adopt three kinds of emotional labor strategies when controlling and managing own emotions.

Table 1. Result of open questionnaire

\begin{tabular}{|c|c|c|c|}
\hline \multirow{2}{*}{ Type } & \multicolumn{2}{|c|}{ Details } & \multirow{2}{*}{ Main description } \\
\hline & (Number) & (Percentage) & \\
\hline \multirow[t]{8}{*}{ Emotional labor } & \multicolumn{2}{|c|}{ Surface acting } & Display the required emotion of the school \\
\hline & \multirow{2}{*}{\multicolumn{2}{|c|}{ (28) $(27.2 \%)$}} & Be patient and follow the requirement of school on emotion \\
\hline & & & Suppress own real emotion \\
\hline & \multicolumn{2}{|c|}{ Active deep acting } & Self-criticism as much as possible \\
\hline & \multirow[t]{2}{*}{$(45)$} & $(43.7 \%)$ & Try to adjust self (find a balance point ) \\
\hline & & & Adjust according to the students' need \\
\hline & \multicolumn{2}{|c|}{ Passive deep acting } & Have a calm and peaceful attitude and positive spirit \\
\hline & $(14)$ & $(13.6 \%)$ & Sincerely display the emotion which should be displayed \\
\hline $\begin{array}{l}\text { No emotional } \\
\text { labor }\end{array}$ & $(16)$ & $(15.5 \%)$ & $\begin{array}{l}\text { Abreact emotion (complain, abuse, condemn, abreact with force), keep silent, apathy, be } \\
\text { indifferent }\end{array}$ \\
\hline
\end{tabular}

It can be seen from Table 1 that $15.5 \%$ of 103 teachers do not involve emotional labor, but give vent to emotion; among teachers who use emotional labor strategy, most of the teachers use active deep acting, i.e., actively adjusting and changing own emotion so as to express the required emotion of the school as far as possible; $28 \%$ of the teachers suppress and control own true feeling so as to display the required emotion of the school. Although this item aims to understand the teacher's surface acting and active deep acting, a few teachers (13.6\%) also show passive deep acting. It can be seen from the above analysis that surface acting, active deep acting and passive deep acting are effective dimensions of teachers' emotional labor of China. 


\subsection{Preliminary Questionnaire on Emotional Labor among Primary and Secondary School Teachers}

\subsubsection{Formation of Preliminary Questionnaire}

In order to determine the dimensions and items of questionnaire on emotional labor among primary and secondary school teachers, 286 primary and secondary school teachers were investigated, including 152 male teachers, accounting for $57.6 \%$ of the respondents, and 112 female teachers, accounting for $42.4 \%$ of the respondents. There are 264 effective questionnaires.

The first step of questionnaire development is to produce a set of items whose ideal size should be 2-4 times of the final items. In this study, it is expected that each dimension involves 5 items and the items of preliminary survey questionnaire is 2-3 times more than that of ideal questionnaire, so the preliminary survey questionnaire should at least involve 30 items.

Because the results of open questionnaire survey in this study support the literature analysis result involving three dimensions, the items of this study are mainly from existing research questionnaires and analysis of the literatures. First, the items involving surface acting and deep acting from existing emotional questionnaires are extracted. It is found that there are many items involving surface acting and active deep acting, but items on passive deep acting are few. Based on theoretical thinking and study of existing questionnaire, preliminary survey questionnaire is designed with 40 items, of which, 24 items are from existing questionnaires and 16 are from literature analysis.

167 teachers participated in pretest with 40 preliminary items. In the process of test, researchers talked with partial primary and secondary school teachers (36) to know their understanding of each item in the questionnaire. After communication, there are 4 items which are not clear in meaning or understood difficultly. Exploratory factor analysis is carried out for pre questionnaire, and according to principle of item deletion of exploratory factor analysis, 10 items are deleted and 26 items are maintained and used to made preliminary survey questionnaire.

\subsubsection{Formation of Preliminary Questionnaire}

According to the research results of predictive questionnaire, questionnaire on emotional labor among primary and secondary school teachers involving 26 items are developed for preliminary test and retest is carried out for 65 teachers after 2 months.

(1) Item analysis

The scale is ordered by total score from high to the end, and top $27 \%$ are known as high score group, and later $27 \%$ are considered as low score group. Independent samples $t$ test is carried out for the average score of each item in high score group and low score group. If the difference of the item in score between high and low score group fails to reach the significant level, the item is eliminated. Secondly, correlation between each item and total score of the scale is calculated, and the items of low correlation are eliminated. According to item analysis result, the CR of 26 items reaches the significance level $(P<0.01)$, and the correlation coefficient between each item and the total score of the scale is between 0.233and 0.636, reaching significance level $(\mathrm{P}<0.001)$, which shows all items have better identification. The specific results see Table 2.

Table 2. Item analysis of preliminary questionnaire on emotional labor among primary and secondary school teachers

\begin{tabular}{|c|c|c|c|c|c|}
\hline 1 & $1.004 * * *$ & $0.400 * * *$ & 14 & $2.657 * * *$ & $0.367 * * *$ \\
\hline 2 & $0.509 * * *$ & $0.551 * * *$ & 15 & $6.499^{*}$ & $0.269^{* * *}$ \\
\hline 3 & $1.262 * * *$ & $0.508 * * *$ & 16 & $3.416^{* * * *}$ & $0.527 * * *$ \\
\hline 4 & $1.677^{* *}$ & $0.263^{* * *}$ & 17 & $0.487 * * *$ & $0.503^{* * *}$ \\
\hline 5 & $3.360 * * *$ & $0.435 * * *$ & 18 & $3.561 * * *$ & $0.560^{* * * *}$ \\
\hline 6 & $4.223 * * *$ & $0.470^{* * * *}$ & 19 & $10.930 * * *$ & $0.571 * * *$ \\
\hline 7 & $4.343^{* * *}$ & $0.623 * * *$ & 20 & $0.095 * * *$ & $0.547 * * *$ \\
\hline 8 & $21.107 * * *$ & $0.345^{* * *}$ & 21 & $6.138 * * *$ & $0.636^{* * * *}$ \\
\hline 9 & $3.410^{* * * *}$ & $0.582 * * *$ & 22 & $0.613^{* * * *}$ & $0.612 * * *$ \\
\hline 10 & $3.650^{* *}$ & $0.317 * * *$ & 23 & $4.644 * * *$ & $0.488^{* * *}$ \\
\hline 11 & $1.809 * * *$ & $0.432 * * *$ & 24 & $4.469 * * *$ & $0.564 * * *$ \\
\hline 12 & $9.679 * *$ & $0.355^{* * *}$ & 25 & $0.406^{* * * *}$ & $0.583^{* * *} *$ \\
\hline 13 & $2.048 * * *$ & $0.584 * * *$ & 26 & $0.411 * *$ & $0.233 * * *$ \\
\hline
\end{tabular}

Note: $* P<0.05, * * P<0.01, * * * P<0.001$, similarly hereinafter. 


\section{(2) Exploratory Factor Analysis}

\section{A. Aptness of sample for factor analysis}

Aptness of sample should be tested before factor analysis to identify and confirm the basic structure of all items so as to reduce the number of factors. Bartlett ball test is used in this study, with its value of 1110.375, significance level of 0.000 , which verifies that the sample is suitable for factor analysis. KMO, a statistics variable which compares the simple correlation coefficient and partial correlation coefficient between observed variables, is between 0 and 1 . When partial correlation coefficient of all the variables is far less than square of simple correlation coefficient, KMO is close to 1 . The smaller KMO value is, the more inappropriate for observed variables are with factor analysis. This index is usually explained with the following standards: when KMO is more than 0.9 , the sample is very suitable for factor analysis; when KMO is between 0.8 and 0.9 , the sample is relatively suitable for factor analysis; when between 0.7 and 0.8 , the sample can be with factor analysis; when between 0.6 and 0.7 , factor analysis for the sample is general; when less than 0.6, the sample is not suitable for factor analysis (Rober.B.S.etc.al.,1998). KMO test value of this study is 0.850 , which shows the sample is relatively suitable for factor analysis.

\section{B. Item screening}

Item screening of factor analysis should follow the following statistical indicators:

(1) Obvious steep slope appears in scree plot in scree test and those factors at the area of upper left of figure with obvious elbow in scree plot are maintained.

(2) Factor load. Factor load should more than 0.4, only involving one factor. According to Kavsek, Seiffge-Krenke (1996) rule, the item with the factor load less than 0.4 will be eliminated.

(3) Communality. Communality of item, also known as Common variance, refers to estimate value of reliability coefficient of all items (sum of square of load of item in all public factors). According to Kavsek,Seiffge-Krenke (1996) law, the items with communality less than 0.16 should be eliminated.

(4) One factor should at least have more than three items and internal item consistency of a factor is high. There are 16 items in this study with eigenvalue more than 1 , independent factor load more than 0.4 and communality more than 0.2 to compose a preliminary questionnaire involving a three-factor model. Specific results are shown in Table 3.

Table 3. Results of exploratory factor analysis of preliminary questionnaire on emotional labor among primary and secondary school teachers

\begin{tabular}{ccccccc}
\hline Item & Factor 1 & Factor 2 & Factor 3 & Communality & $\begin{array}{c}\text { Characteristic } \\
\text { value }\end{array}$ & $\begin{array}{c}\text { Explanation } \\
\text { rate }\end{array}$ \\
\hline 11 & 0.745 & & & 0.592 & & \\
23 & 0.733 & & & 0.576 & & \\
25 & 0.646 & & & 0.508 & 4.464 & 27.901 \\
21 & 0.607 & & & 0.498 & & \\
22 & 0.600 & 0.708 & & 0.556 & & \\
2 & & 0.703 & & 0.505 & & \\
7 & & 0.638 & & 0.559 & & \\
16 & & 0.618 & & 0.455 & 2.376 & 14.850 \\
19 & & 0.563 & & 0.428 & & \\
9 & & 0.471 & 0.766 & 0.400 & & \\
13 & & & 0.589 & & \\
12 & & & 0.748 & 0.560 & & \\
10 & & & 0.642 & 0.431 & 1.194 & 7.465 \\
8 & & & 0.626 & 0.535 & & \\
4 & & 0.583 & 0.394 & & \\
\hline
\end{tabular}

It can be seen from Table 3 that three factors explain $0.216 \%$ of the total variance, and the minimum load of the item is 0.766 , the maximum load is 0.766 , and communality of all items are between 0.394 and 0.592 . Naming for the factors follows the following principles: (1) refers to the idea of theory model: see which dimension the item belongs to and involves the most items; (2) refers to the load of the factor that the item belongs to, i.e., name the factor according to the implied meaning of item with higher load. According to this principle, three factors are extracted: the first factor involves 5 items, characteristic value is 4.464, explanation rate of variance after maximum variance rotation is $27.901 \%$, and all the items come from passive deep acting, so this factor is named as "passive deep acting". The second factor involves 6 items, its characteristic value is 2.376, and explanation rate of variance after maximum variance rotation is $14.850 \%$, and all the items come from active deep acting, so this factor is named as " active deep acting" . The third factor involves 5 items, its characteristic value is 1.194, and explanation rate of variance after maximum variance rotation is $7.465 \%$, and all the items come from surface acting, so this factor is named as "surface acting". The 
structure and items after factor analysis are rearranged to form the preliminary questionnaire (See Table 5). After large-scale test, official questionnaire on emotional labor for primary and secondary school teachers is formed.

\section{Formation of Questionnaire on Emotional Labor for Primary and Secondary School Teachers}

Preliminary questionnaire (16 items) after adjustment is used to test 521 primary and secondary school teachers and 68 invalid questionnaires are eliminated. Actual statistical data involves 453 teachers, of whom, 310 teachers from primary school, 353 from middle school, 202 male teachers and 461 female teachers. Exploratory factor analysis is used to further modify the preliminary questionnaire so as to form formal questionnaire, and the reliability and validity of the formal questionnaire are tested.

\subsection{Exploratory Factor Analysis}

The value of Bartlett ball test is1997.832, significance level is 0.000 , which proves the sample is suitable for factor analysis, and KMO test value is 0.852 , indicating the sample is relatively suitable for factor analysis.

By using principal component analysis, there are 3 factors whose characteristic value after orthogonal rotation is more than 1 and factor load is more than 0.4. It can be seen from rubble diagram (see Figure 1) that an obvious steep slope appears after the third factor, and general explanation rate for questionnaire is $50.435 \%$. The specific factor analysis results are shown in Table 4.

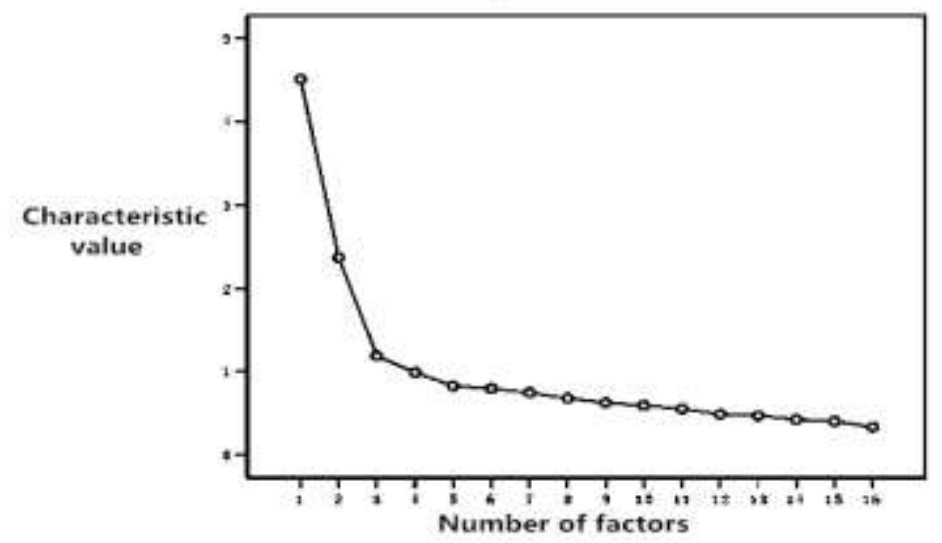

Figure 1. Scree plot

Table 4. Results of exploratory factor analysis of questionnaire on emotional labor among primary and secondary school teachers

\begin{tabular}{ccccccc}
\hline Item & Factor 1 & Factor 2 & Factor 3 & Communality & Characteristic value & Explanation rate \\
\hline 15 & 0.767 & & & 0.619 & & \\
7 & 0.730 & & & 0.560 & 4.512 & \\
14 & 0.641 & & & 0.563 & & \\
13 & 0.606 & & & 0.564 & & \\
16 & 0.599 & & & 0.400 & & \\
9 & 0.548 & & & 0.452 & & \\
11 & & 0.703 & & 0.550 & & \\
3 & & 0.631 & & 0.506 & & \\
12 & & 0.630 & & 0.521 & & \\
5 & & 0.594 & & 0.496 & & \\
1 & & 0.576 & 0.693 & 0.357 & & \\
8 & & & 0.610 & & \\
6 & & & 0.688 & 0.513 & & \\
4 & & & 0.662 & 0.569 & & \\
2 & & & 0.652 & 0.431 & & \\
10 & & & 0.570 & 0.357 & & \\
\hline
\end{tabular}

It can be seen from the results of exploratory factor analysis that questions 9 which belongs to the item of active deep acting is rotated to the factor of passive deep acting, so this item is eliminated. The remaining 15 items are performed exploratory factor analysis again, and 3 factors with eigenvalue more than 1 and factor load more than 0.4 is obtained. The specific results are shown in Table 5. 
Table 5. Results of exploratory factor analysis of formal questionnaire on emotional labor among primary and secondary school teachers

\begin{tabular}{|c|c|c|}
\hline \multicolumn{3}{|r|}{ Factor 1: Passive deep acting(characterize value: 2.328 , explanation rate: $15.518 \%$ ) } \\
\hline 15 & 0.762 & The emotion which I display before the students is real \\
\hline 7 & 0.731 & The emotion which I feel in the work is consistent with that I display \\
\hline 14 & 0.622 & $\begin{array}{l}\text { It is very easy for me to feel the students' emotion in the process of } \\
\text { communication with students }\end{array}$ \\
\hline 16 & 0.604 & It is natural and easy for me to response my students' emotion \\
\hline \multirow[t]{2}{*}{13} & 0.579 & $\begin{array}{l}\text { The emotion I display before the students is consistent with the required } \\
\text { emotion of the school }\end{array}$ \\
\hline & Factor 2 & Active deep acting (characterize value:4.171, explanation rate: $27.807 \%$ ) \\
\hline 11 & 0.703 & I always remind of trying to feel the required emotion of the school. \\
\hline 12 & 0.646 & $\begin{array}{l}\text { When I need display joyful emotion before the students, I will imagine the } \\
\text { things in life which make me happy }\end{array}$ \\
\hline 3 & 0.645 & $\begin{array}{l}\text { I will try to control my emotion in work as much as possible and sincerely } \\
\text { display positive emotion }\end{array}$ \\
\hline 5 & 0.617 & $\begin{array}{l}\text { If I must display a certain emotion (such as passion, optimism, love and } \\
\text { kindness, etc) before students, I will adjust own emotion to make the } \\
\text { emotion displayed from the heart }\end{array}$ \\
\hline \multirow[t]{2}{*}{1} & 0.586 & $\begin{array}{l}\text { I will actively feel the required emotion of the school, not only change my } \\
\text { expression }\end{array}$ \\
\hline & Factor & 3: Surface acting (Characterize value: 2.328 , explanation rate: $15.518 \%$ ) \\
\hline 8 & 0.703 & I often intend my own emotion when facing the students \\
\hline 6 & 0.686 & I will intend to be in good mood when I get on with the students \\
\hline 2 & 0.653 & I act in a play when displaying appropriate expression and attitude in work \\
\hline 4 & 0.653 & $\begin{array}{l}\text { It is feasible that I only need display the required emotions (such as passion, } \\
\text { optimism, love, trust, friendliness, kindness) in work when necessary }\end{array}$ \\
\hline 10 & .578 & The emotion I display before the students in the class is not the one I really feel \\
\hline
\end{tabular}

The results show that the overall explanation rate of questionnaire is $51.246 \%$, higher than that when question 9 is not eliminated, which shows the structure of questionnaire on emotional labor with 15 items is better than that of the questionnaire with 16 items. From the perspective of the structure of factor analysis, this structure is consistent with our ideal structure. Hence, three-dimension questionnaire on emotional labor involving 15 items is considered as the formal one for primary and secondary school teachers.

\subsection{Analysis of Reliability and Validity}

\subsubsection{Analysis of Reliability of the Questionnaire}

Cronbach's Alpha $(\alpha)$ coefficient (homogeneity reliability) and stability coefficient (retest reliability) are used in this study for reliability test. The results are shown in Table 6.

Table 6. Coefficient of internal consistency and retest variability coefficient of questionnaire on emotional labor among primary and secondary school teachers

\begin{tabular}{|c|c|c|c|}
\hline Factor & Cronbach's Alpha $(\alpha)$ & coefficient $(n=453)$ & Retest variability coefficient $(\mathrm{n}=65)$ \\
\hline Surface acting & & 0.681 & 0.802 \\
\hline Active deep acting & & 0.741 & 0.895 \\
\hline Active deep acting & & 0.779 & 0.816 \\
\hline Total scale & & 0.777 & 0.856 \\
\hline
\end{tabular}

It can be seen from Table 6 that Cronbach's Alpha $(\alpha)$ coefficient of self-edited questionnaire on emotional labor among primary and secondary school teachers is between 0.681 and 0.779 , retest reliability coefficient is between 0.802 and 0.895 , total Cronbach 's Alpha (a) coefficient of the questionnaire is 0.777 , retest reliability coefficient is 0.856 . From this point, this questionnaire has good reliability. 


\subsubsection{Validity Test of the Questionnaire}

The content validity of the questionnaire is ensured by normative research procedure. In addition, structure validity and criterion validity of the questionnaire are tested.

\section{(1) Structure validity}

Factor analysis is a useful method to test structure validity. According to psychologist Tuker's theory, when correlation between score of item and the total score of the test is between 0.30 and 0.80 and correlation between groups of the item is between 0.10 and 0.60, the validity of the test is satisfactory (Dai Zhongheng, 1987). Correlation among all factors and between the score of the factor and the total score of the questionnaire are shown in Table 7.

Table 7. Correlation between all dimensions of questionnaire on emotional labor among primary and middle teachers and total scale

\begin{tabular}{cccc}
\hline & Surface acting & $\begin{array}{c}\text { Active deep } \\
\text { acting }\end{array}$ & $\begin{array}{c}\text { Active deep } \\
\text { acting }\end{array}$ \\
\hline Surface acting & 1.000 & & \\
Passive deep acting & $0.217^{* *}$ & 1.000 & \\
Active deep acting & 0.026 & $0.557^{* *}$ & 1.000 \\
$\begin{array}{c}\text { Total score of } \\
\text { emotional labor }\end{array}$ & $0.611^{* *}$ & $0.819^{* *}$ & $0.714(* *)$ \\
\hline
\end{tabular}

It can be seen from Table 7 that the correlation degree between all dimensions and the overall scale is higher, with correlation coefficient between 0.611 and 0.819 , achieving significant level $(\mathrm{P}<0.001)$, which shows that all factors can better reflect the content of the questionnaire. From correlation of all factors of the questionnaire, surface acting is not correlated with passive deep acting, which is because the emotion is disguised in surface acting, while it is not the case in passive deep acting. Hence both of them are two completely different kinds of acting strategy. The correlation between active deep acting and surface acting is 0.217 , and the correlation between active deep acting and passive deep acting is 0.557 , which shows moderate correlation and less than that between the factor and the overall questionnaire, reaching significant difference $(\mathrm{P}<0.001)$. Hence, the questionnaire has good structure validity.

(2) Criterion validity

Because there is no specialized questionnaire on emotional labor among teachers, we use the questionnaire on emotional labor developed by Diefendorff (2005) which is consistent with this research structure. This questionnaire is suitable for testing the employee's emotional labor in service industry, so the word "customer" in the questionnaire is replaced by "student". The questionnaire includes three dimensions and 14 items. The dimension surface acting involves 7 items, passive deep acting involves 3 items and active deep acting involves 4 items.

54 primary and secondary school teachers participate in the test with two questionnaires. The Pearson correlation between self-edited questionnaire and Diefendorff's (2005) questionnaire and significance test results are shown in Table 8 .

Table 8. Correlation between self-edited questionnaire on emotional labor among primary and middle school teachers and Diefendorff's (2005) questionnaire

\begin{tabular}{|c|c|c|c|c|}
\hline & $\begin{array}{l}\text { Surface acting } \\
\text { (Questionnaire } \\
\text { among employees) }\end{array}$ & $\begin{array}{l}\text { Active deep acting } \\
\text { (Questionnaire } \\
\text { among employees) }\end{array}$ & $\begin{array}{l}\text { Passive deep acting } \\
\text { (Questionnaire } \\
\text { among employees) }\end{array}$ & $\begin{array}{l}\text { Total score of questionnaire } \\
\text { onemotional labor among } \\
\text { employees in service industry }\end{array}$ \\
\hline $\begin{array}{c}\text { Surface acting } \\
\text { (Questionnaire among teachers) }\end{array}$ & $0.540 * *$ & & & \\
\hline $\begin{array}{l}\text { Active deep acting(Questionnaire } \\
\text { among teachers) }\end{array}$ & 0.210 & $0.550 * *$ & & \\
\hline $\begin{array}{l}\text { Passive deep acting(Questionnaire } \\
\text { among teachers) }\end{array}$ & -0.228 & 0.238 & $0.316^{*}$ & \\
\hline $\begin{array}{l}\text { Total score of questionnaire on } \\
\text { emotional labor among primary and } \\
\text { middle school teachers }\end{array}$ & 0.099 & $0.610 * *$ & 0.124 & $0.405 * *$ \\
\hline
\end{tabular}

It can be seen from Table 8 that surface acting, active deep acting and passive deep acting as well as total score of self-edited questionnaire for emotional labor among primary and secondary school teachers and Diefendorff's (2005) questionnaire are significantly correlative in pairs, and correlation coefficient is between 0.316 and 0.550 , which is moderate correlation. It can be seen that self-edited questionnaire in this study has good criterion related validity. 


\subsection{Confirmatory Factor Analysis of Questionnaire on Emotional Labor among Primary and Secondary School Teachers}

Questionnaire on emotional labor (15 items) is used to test primary and secondary school teachers of several provinces and cities. After eliminating the questionnaire with incomplete information and answer, actual statistical data involves 663 questionnaires, of which, 310 is from primary school and 353 is from middle school; there are 202male teachers and 461 female teachers. Confirmatory factor analysis further verifies the structure validity of questionnaire on emotional labor.

\subsubsection{Model Hypothesis}

Hypothesis: primary and secondary school teachers' emotional labor involves three elements, including surface acting, active deep acting and passive deep acting (See Figure 2).

Because both active deep acting and passive deep acting belong to deep acting and have medium correlation (correlation coefficient is $0.557 * *$ in this study), teacher's emotional labor may be a two-factor structure (see Figure 3 ) in order to compare with three-factor structure.

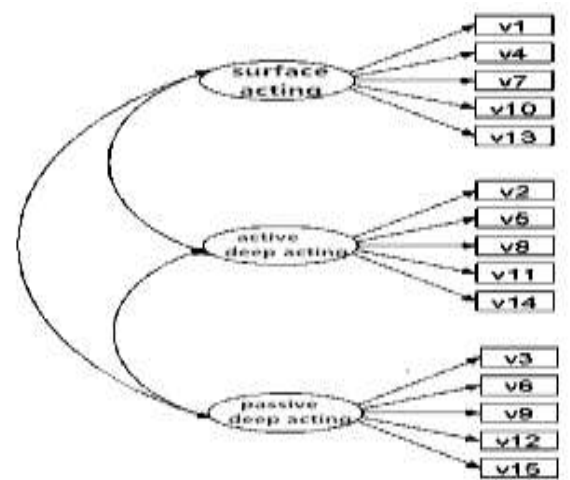

Figure 2. Three-factor structure Schematic diagramof teachers' emotional work

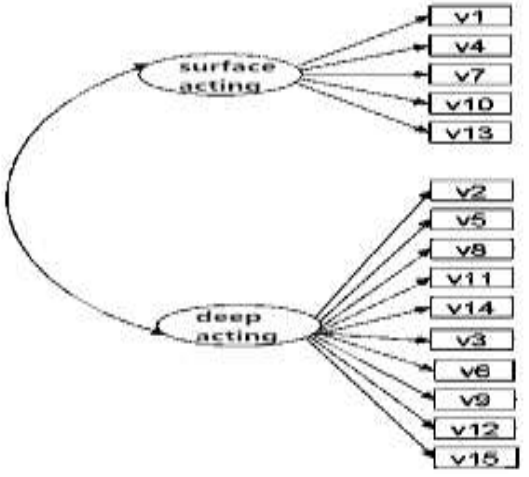

Figure 3. Two-factor structure Schematic diagram of teachers' emotional work

\subsubsection{Results}

Confirmatory factor analysis is used to verify the suitability of the model. On the one hand, correlation between exogenous latent variable and observed variable and their load reflect the path between the factors. On the other hand, fitting index reflects the fitting degree of reaction model. The following indexes are usually considered:

(1) x2 (chi - square) test. Ratio of chi-square value to degree of freedom (x2 / df) is used as alternative test index. Expected value in theory is 1 , and the criteria for accepted good model and data fitting is $\mathrm{x}^{2} / \mathrm{df}<5$.

(2) Fitting index. The model of good fitting should involve: low $\mathrm{x}^{2}$ and SRMR value, such as $\mathrm{x}^{2} / \mathrm{df}<5$, SRMR $<0.080$; range of GFI, AGFI, NNFI, CFI between 0 and 1, the closer to 1, the better, which shows that theoretical model can indicate the relationship between the original data and the better fitting degree of the model.

Three factors structure and two factors structure of questionnaire on emotional labor among primary and secondary school teachers are carried out confirmatory factor analysis, respectively. Specific results are shown in Table 9.

Table 9. Fitting index of three-factor model and two-factor model of questionnaire on emotional labor among primary and secondary school teachers

\begin{tabular}{cccccccccccc}
\hline Model & $\mathrm{x}^{2}$ & $\mathrm{df}$ & $\mathrm{x}^{2} / \mathrm{df}$ & GFI & AGFI & NFI & NNFI & CFI & IFI & RMSEA & AIC \\
\hline M1 & 220.194 & 87 & 2.531 & 0.957 & 0.940 & 0.903 & 0.926 & 0.938 & 0.939 & 0.048 & 286.194 \\
M2 & 325.256 & 89 & 3.655 & 0.931 & 0.907 & 0.856 & 0.871 & 0.891 & 0.891 & 0.063 & 387.256
\end{tabular}

Note: M1 represents three-factor model of emotional labor among primary and secondary school teachers; M2 represents two-factor model of emotional labor.

It can be seen from Table 9 that $\mathrm{x}^{2} / \mathrm{df}$ of three-factor model of questionnaire is less than 5, RMSEA is less than 0.08 and AIC is less than that of two-factor model(it is generally believed that the smaller the AIC, the more frugal the model), and other fitting indexes including GFI, AGFI, NFI, NNFI, CFI, IFI are more than 0.90, which the fitting of model and data is very good. It is can be seen through comparison between two models that through fitting indexes of two-factor 
model is good, all indexes of three-factor model is better, showing three-factor model is more frugal and clearer in meaning. According to this, the hypothesis of three-factor model of the questionnaire on emotional labor among primary and secondary school teachers is established. The constructed model is as follows (see Figure 4).

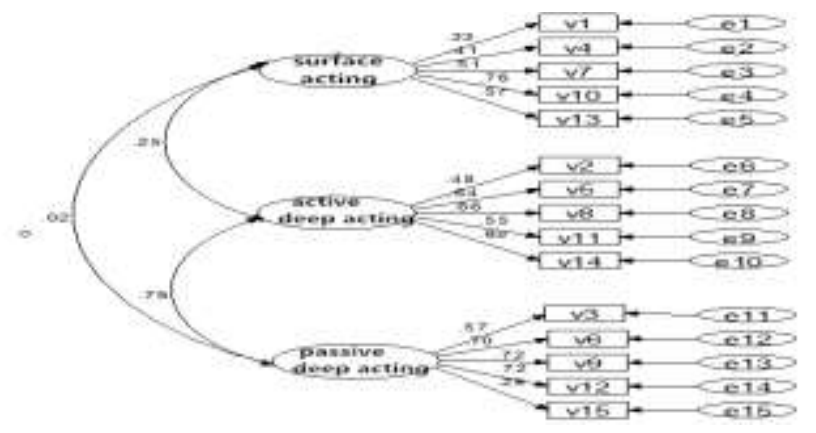

Figure 4. Fitting of confirmatory factor analysis of three-factor structure of questionnaire on emotional labor among teachers

\section{Discussion}

\subsection{Structure of Primary and Secondary School Teachers' Emotional Labor}

Through open questionnaire investigation, it is found that when there is difference between primary and secondary school teachers' emotional management and required emotion of school, they adopt emotional labor strategies including surface acting, active acting and passive acting, which verifies that theoretical structure of teacher's emotional labor is reasonable.

Through exploratory factor analysis and confirmatory factor analysis, emotional labor structure of three factors including surface acting, active deep acting and passive deep acting is obtained. This structure is consistent with that in our thought and research structure of Diefendorff, Croyle, \& Gosserand, et al (2005).

Existing studies mostly involve surface acting and active deep acting of emotional labor, and this study through open questionnaire and factor analysis finds that passive deep acting is also an important element of emotional labor, which also verifies Ashforth \& Humphrey(1993), Kruml and Geddes's (2000) idea that passive deep acting, i.e., spontaneous real experience and expression of desired emotion is also the important part of emotional labor.

\subsection{Reliability and Validity of Questionnaire on Emotional Labor among Primary and Secondary School Teachers}

The development of this self-edited questionnaire on emotional labor among primary and secondary school teachers in this study strictly follows the specifications. The dimensions of questionnaire on emotional labor are determined through theoretical analysis combined with related test tools. Partial items are directly introduced from existing emotional test tools and confirmed by open questionnaire. These measures to a certain extent to ensure self-edited questionnaire on emotional labor can largely reflect the actual situation of China's primary and secondary school teachers' emotional labor.

Exploratory factor analysis and confirmatory factor analysis are necessary for development of questionnaire. For a good test, the results of these two analyses should be consistent and stable. One of purposes of this study is to develop a questionnaire on emotional labor for primary and secondary school teachers with good reliability and validity. Statistical analysis methods such as principal component analysis (for the classification of data), factor analysis (reduce items and obtain factor model), item analysis (analysis of identification of questions kept), internal consistency analysis and correlation analysis (reliability and validity test) and confirmatory factor analysis (measured data of variables are used to test the validity of the hypothesis model) are used and official questionnaire on emotional labor among primary and secondary school teachers of China are developed according to strict procedure. The questionnaire with 15 items involves three dimensions, including surface acting, passive deep acting and active deep acting.

From the data obtained in this research, the internal consistency coefficient of this self-edited questionnaire of emotional labor among primary and secondary school teachers is between 0.681 and 0.779 , retest reliability coefficient is between 0.802 and 0.895 ; Cronbach 's Alpha (a) coefficient of the whole questionnaire is 0.777 , and retest reliability coefficient is 0.856 . These data indicates that this questionnaire has good reliability. All dimensions of questionnaire is highly correlated to the whole questionnaire, and the structure validity coefficient is between 0.611 and 0.819 (P < 0.001), with statistically significant difference, which shows all factors reflect the content that the questionnaire need measure. From the perspective of validity, although there is no dedicated questionnaire on emotional labor among teachers, the score of surface acting, active deep acting and passive deep acting in the modified questionnaire are significantly correlated with the total score in pairs, with correlation coefficient between 0.316 and 0.550 (moderate 
correlation), showing statistically significant difference, which shows the questionnaire for emotional labor among primary and secondary school teachers has good reliability and validity and the questionnaire can be used to study emotional labor among primary and secondary school teachers of China. However, the concept, scientific analysis and definition of emotional labor of primary and secondary school teachers are in the exploratory stage, so dimension structure obtained in this study remains to be verified by other researchers.

\section{Conclusion}

Based on the definition of structural dimension of teacher's emotional labor, the questionnaire is developed and it is found through exploratory factor analysis that teacher's emotional labor involves three dimensions including surface acting, active deep acting and passive deep acting; the questionnaire has good reliability and validity; confirmatory factor analysis shows that emotional labor questionnaire involving three factors is established, which further verifies the validity of scale for emotional labor among primary and secondary school teachers.

\section{Acknowledgements}

This study was supported by the National social science fund "twelfth five-year" plan of 2012 annual general education subjects : "primary and secondary school teachers' autonomy development and its relationship with mental health research" (approval number: BBA120016).

\section{References}

Adelmann, P. K. (1989). Emotional labor and employee well-being. University of Michigan.

Ashforth, B. E., \& Humphrey, R. H. (1993). Emotional labor in service roles: The influence of identity. Academy of management review, 18(1), 88-115. http://dx.doi.org/10.5465/AMR.1993.3997508

Diefendorff, J. M., Croyle, M. H., \& Gosserand, R. H. (2005). The dimensionality and antecedents of emotional labor strategies. Journal of Vocational Behavior, 66(2), 339-357. http://dx.doi.org/10.1016/j.jvb.2004.02.001

Diefendorff, J. M., \& Gosserand, R. H. (2003). Understanding the emotional labor process: A control theory perspective. Journal of Organizational Behavior, 24(8), 945-959. http://dx.doi.org/10.1002/job.230

Goodwin, R. E., Groth, M., \& Frenkel, S. J. (2011). Relationships between emotional labor, job performance, and turnover. Journal of Vocational Behavior, 79(2), 538-548. http://dx.doi.org/10.1016/j.jvb.2011.03.001

Grandey, A. A. (2000). Emotional regulation in the workplace: A new way to conceptualize emotional labor. Journal of occupational health psychology, 5(1), 95. http://dx.doi.org/10.1037/1076-8998.5.1.95

Grandey, A. A. (2003). When "the show must go on": Surface acting and deep acting as determinants of emotional exhaustion and peer-rated service delivery. Academy of management Journal, 46(1), 86-96. http://dx.doi.org/10.2307/30040678

Hochschild, A. R. (1979). Emotion work, feeling rules, and social structure. American journal of sociology, 551-575. http://dx.doi.org/10.1086/227049

Hochschild Arlie, R. (1983). The Managed Heart: Commercialization of Human Feeling: Berkeley, University of California Press.

Kruml, S. M., \& Geddes, D. (2000). Exploring the Dimensions of Emotional Labor The Heart of Hochschild's Work. Management communication quarterly, 14(1), 8-49. http://dx.doi.org/10.1177/0893318900141002

Morris, J. A., \& Feldman, D. C. (1996). The dimensions, antecedents, and consequences of emotional labor. Academy of management review, 21(4), 986-1010. http://dx.doi.org/10.5465/AMR.1996.9704071861

Yin, H. (2012). Adaptation and validation of the teacher emotional labour strategy scale in China. Educational Psychology, 32(4), 451-465. http://dx.doi.org/10.1080/01443410.2012.674488

Liao, X. (2011). Development and preleminary application of questionaire on emotional labor among middle school teachers. Zhejiang Normal University.

Sun, J., \& Qiao, J. (2005). Current situation of study on emotional labor. Advances in Psychological Science, 13(1), $85-90$.

Zhang, H., Ling, W., \& Fang, L. (2006). Overview of study on emotional labor. Advances in Psychological Science, 14(1), 111-119.

\section{$((c))$ EY}

This work is licensed under a Creative Commons Attribution 3.0 License. 